\title{
Menstrual cups and cash transfer to reduce sexual and reproductive harm and school dropout in adolescent schoolgirls: study protocol of a cluster-randomised controlled trial in western Kenya
}

Garazi Zulaika' (D, Daniel Kwaro², Elizabeth Nyothach², Duolao Wang', Emily Zielinski-Gutierrez³, Linda Mason', Alie Eleveld ${ }^{4}$, Tao Chen ${ }^{1}$, Emily Kerubo², Annemieke van Eijk' , Cheryl Pace ${ }^{1}$, David Obor ${ }^{2}$, Jane Juma², Boaz Oyaro², Louis Niessen', Godfrey Bigogo², Isaac Ngere5, Carl Henry', Maxwell Majiwa², Clayton O. Onyango4,

Feiko O. ter Kuile ${ }^{1}$ and Penelope A. Phillips-Howard ${ }^{1 *}$

\begin{abstract}
Background: Adolescent girls in sub-Saharan Africa are disproportionally vulnerable to sexual and reproductive health (SRH) harms. In western Kenya, where unprotected transactional sex is common, young females face higher rates of school dropout, often due to pregnancy, and sexually transmitted infections (STIs), including HIV. Staying in school has shown to protect girls against early marriage, teen pregnancy, and HIV infection. This study evaluates the impact of menstrual cups and cash transfer interventions on a composite of deleterious outcomes (HIV, HSV-2, and school dropout) when given to secondary schoolgirls in western Kenya, with the aim to inform evidence-based policy to improve girls' health, school equity, and life-chances.

Methods: Single site, 4-arm, cluster randomised controlled superiority trial. Secondary schools are the unit of randomisation, with schoolgirls as the unit of measurement. Schools will be randomised into one of four intervention arms using a 1:1:1:1 ratio and block randomisation: (1) menstrual cup arm; (2) cash transfer arm, (3) cups and cash combined intervention arm, or (4) control arm. National and county agreement, and school level consent will be obtained prior to recruitment of schools, with parent consent and girls' assent obtained for participant enrolment. Participants will be trained on safe use of interventions, with all arms receiving puberty and hygiene education. Annually, the state of latrines, water availability, water treatment, handwashing units and soap in schools will be measured. The primary endpoint is a composite of incident HIV, HSV-2, and all-cause school dropout, after 3 years follow-up. School dropout will be monitored each term via school registers and confirmed through home visits. HIV and HSV-2 incident infections and risk factors will be measured at baseline, mid-line and end-line. Intention to treat analysis will be conducted among all enrolled participants. Focus group discussions will provide contextual information on uptake of interventions. Monitoring for safety will occur throughout.
\end{abstract}

Discussion: If proved safe and effective, the interventions offer a potential contribution toward girls' schooling, health, and equity in low- and middle-income countries.

(Continued on next page)

\footnotetext{
* Correspondence: Penelope.Phillips-howard@|stmed.ac.uk

'Department of Clinical Sciences, Liverpool School of Tropical Medicine,

Pembroke Place, Liverpool L3 5QA, UK

Full list of author information is available at the end of the article
}

(c) The Author(s). 2019 Open Access This article is distributed under the terms of the Creative Commons Attribution 4.0 International License (http://creativecommons.org/licenses/by/4.0/), which permits unrestricted use, distribution, and reproduction in any medium, provided you give appropriate credit to the original author(s) and the source, provide a link to the Creative Commons license, and indicate if changes were made. The Creative Commons Public Domain Dedication waiver (http://creativecommons.org/publicdomain/zero/1.0/) applies to the data made available in this article, unless otherwise stated. 
(Continued from previous page)

Trial registration: ClinicalTrials.gov NCT03051789, 15th February 2017.

Keywords: Sexual and reproductive health, Adolescence, Equity, HIV, HSV-2, Pregnancy, School dropout, Clinical trial, Menstruation, Kenya, Study protocol

\section{Background}

Young persons aged 10-24 years (yr.) make up a quarter of the world's population, contributing 1.8 billion persons of whom approximately $90 \%$ live in low or middleincome countries (LMIC). Adolescence is a critical time of psychological and biological change, and advocacy has increased to identify interventions that protect young peoples' lives [1]. These interventions include ways to protect against sexual and reproductive health $(\mathrm{SRH})$ harms, which are disproportionately high among adolescent girls in sub-Saharan Africa (SSA) [2, 3]. Each year an estimated 14 million girls aged $15-19 \mathrm{yr}$. give birth [2]. Maternal causes kill more girls in this age group than any other cause [2]. Thus, delaying pregnancy to adulthood is important for women's reproductive health and infant survival, as well as girls economic and social empowerment [4]. In much of east and southern Africa including western Kenya, where unprotected transactional sex is common, young females are highly vulnerable to sexually transmitted infections (STIs), including HIV which may result in mother-to-child transmission $[2,3]$. The burden of young female SRH harms is high for individuals, and on their communities and health services, yet sustainable preventive interventions are lacking. Evidence of a positive association between girls' education, and their health and economic potential, has strengthened international resolve to improve educational opportunities for adolescent girls. While SRH education has not been demonstrated to have a large impact on SRH harms [5], staying in school has shown to protect girls against early marriage, teen pregnancy, and HIV infection, with schoolgirls reporting less frequent sex, and fewer partners with less age disparity [6-8]. Building on the Millennium Development Goals (MDG), which focused on primary school attendance, the post2015 Sustainable Development Goals encourage investment in secondary, tertiary and vocational education to build human capital, encourage innovation and spur economic growth [9].

Intervention studies using cash transfer (CT) have demonstrated a protective effect on girls SRH (including HIV, HSV-2) and school indicators [8, 10, 11], although results in other studies have been inconclusive [12, 13]. Dropout before secondary school completion is partly explained by girls' vulnerability once they engage in premarital sex, which is often a precursor to unintended pregnancy or early marriage $[7,14,15]$. Studies have illustrated adolescent girls' vulnerability to transactional or coercive sex, to obtain necessities such as soap, sanitary products, and underwear [16-19]. Products for menstrual hygiene management (MHM) are one such necessity, and their accessibility remains a pervasive problem in LMIC. A lack of MHM materials, awareness, and facilities, as well as stigma, negatively impact girls' school-life [20, 21], and can be a driver of girls' vulnerability to coercive sex. In western Kenya, $10 \%$ of $15 \mathrm{yr}$. old girls self-reported they obtained money through sex to purchase sanitary products [22]. To better understand girls MHM needs in western Kenya, a pilot study in rural primary schools was conducted measuring girls' menstrual practices, uptake, and safety of a reusable menstrual cup (MS Pilot Study) [23, 24]. The pilot results demonstrated acceptability of the menstrual cup [25], with a lower prevalence of STI and bacterial vaginosis found at 9 and 12 month follow-up among girls using the cup when compared to controls [26], and good clinical safety [16]. Prevalence of school dropout after 12 months was lower but inconclusive due to the small sample [26].

To verify the results of the MS Pilot Study and examine the efficacy, safety, and cost-effectiveness of different school-based interventions in improving girls' SRH, schooling, and life-chances in rural western Kenya, a randomized controlled trial was designed with a larger population and follow-up duration. The study is designed to inform evidence-based policy to improve girls' health, school equity and their life-chances which is summarised in this article.

\section{Methods/Design \\ Design overview}

This study is a single site, open-label, 4-arm, schoolcluster randomised controlled superiority trial taking place in Siaya County, western Kenya. Schools are the unit of randomisation (clusters), with girls as the unit of measurement. Schools will be randomly allocated into 4 arms using a 1:1:1:1 ratio and block randomisation to minimise bias. Enrolment will open in the first school term of 2017 after trial registration and continue until we reach the necessary sample. Girls will be followed-up through graduation and into employment or up to 10 
academic terms to determine if they complete secondary school (Form 4), see Additional file 1: Spirit Checklist.

\section{Primary objective}

To determine the impact of menstrual cups or CT alone, or in combination, on a composite of deleterious outcomes (HIV, HSV-2, and school dropout) when given to secondary schoolgirls in western Kenya.

\section{Secondary objectives}

1. To measure the age-specific differences in the acquisition of HIV and HSV-2 infections in secondary schoolgirls and risk factors for incident HIV and HSV-2 infections.

2. To determine the risk, risk factors and reasons for dropout and other school indicators among secondary schoolgirls examining the influence of social, epidemiological, and/or health characteristics.

3. To determine the cost benefit of menstrual cup and CT programmes for schoolgirls by assessing the cost savings of outcomes averted, for individual and combined interventions, and resulting societal impact.

4. To determine the safety of menstrual cup use, including risk of cup contamination over time, serious adverse events, and identify factors that increase or modify this risk.

5. To determine factors affecting how adolescent girls spend CT money, and what training is required to support their financial literacy and decision-making.

6. To determine any adverse outcomes associated with $\mathrm{CT}$ and evaluate ways to mitigate risk.

7. To determine the impact of the interventions on girls' sexual behaviours, including age of sexual début, coerced sex, number of partners, age of partners, pregnancy, condom use and use of contraception.

8. To examine programme implementation for interventions in schools, working with beneficiaries and stakeholders to develop programme implementation packages.

\section{Design considerations}

\section{Why secondary schoolgirls?}

Among schools located in our proposed study area, the dropout rates are higher among girls in secondary when compared to primary school girls. Unpublished school enrolment data for 2015 in the study location shows that only $26 \%$ of primary school girls drop out of primary school compared to $36 \%$ who drop out of secondary school (local school enrolment data, unpublished). These high dropout rates for secondary schoolgirls exert a high burden on the national economy; it is estimated that girls would contribute $48 \%$ more of annual GDP to their economies over their lifetime [4]. Our pilot study found that following the abolition of primary school fees 6 years ago, girls complete primary at a younger age $(<15$ yr). Thus, fewer girls in primary school reach menarche and sexual debut. While prevalence of HIV was low in our primary school cohort $(<1 \%)$, health studies in the same study area have documented very high HIV incidence for secondary school-aged girls, who range in age from 13 to 30 . In one study, HIV prevalence was $8.8 \%$ in $15-19 \mathrm{yr}$. olds, sharply rising from $1.3 \%$ among $13-14 \mathrm{yr}$. olds to $3.3 \%$ in 16 yr. olds and $12.8 \%$ in 18 yr. olds [27]. A similar steep increase by age was seen in HSV-2 prevalence [27]. A high prevalence of STIs was detected in 15-19 yr. old girls in neighbouring Kisumu [28]. In pilot study focus group discussions (FGDs), when asked about reasons for drop out, girls voiced reasons linked to exposure to sexual activity (resulting from alcohol, funeral parties, needs for money, and coercive sex), and these were more frequently stated among older girls [17]. During these FGDs, girls were able to vocalise their concerns about pregnancy risks, and issues around lack of money for school and personal needs. They reported that their menstrual needs were unmet but a high priority and at times compelled them to have sex to obtain money to buy pads [17]. In a separate study in the same area, $10 \%$ of $15 \mathrm{yr}$. olds surveyed reported they had sex for money in order to purchase sanitary pads [22].

\section{Justification for a composite endpoint}

The primary composite endpoint will include incident HIV, HSV-2, and school dropout in girls sero-negative or for both HIV and HSV-2 on enrolment or undetermined serostatus at enrolment (conservatively the sample size allows for $20 \%$ refusal for testing at baseline). The presence of HIV or HSV-2 at enrolment precludes the components from contributing to the primary composite endpoint. Thus, among HIV-negative girls who were HSV-2 positive on enrolment only incident HIV infection and school dropout would contribute to the primary endpoint; among girls who are both HIV and HSV-2 positive on enrolment, only school dropout would contribute. This endpoint represents the key drivers compromising girls' health and life chances into adulthood. The rationale behind this composite endpoint is to increase the power for a given sample and to build a single outcome across all girls regardless of their independent HIV and/or HSV-2 status at enrolment.

\section{Justification for cumulative school dropout}

The cumulative risk of school dropout among secondary schoolgirls is an acute problem in western Kenya; $36 \%$ of girls drop out before the start of the fourth and final year of secondary school due to teen-age pregnancy, lack 
of school funds, illness, work or family commitments, or viewing school as unnecessary [17]. The need for MHM is also perceived as a constant stressor impacting schoollife given that traditional MHM items (rags, paper, etc) leak, cause odour and discomfort, and cause girls to habitually miss school and fall behind. Some evidence suggests that poor MHM even leads some to engage in transactional sex for essential 'luxuries' such as pads and soap [17, 22]. During the pilot study [23-25], we found that use of MHM products (reusable menstrual cups or pads) for at least 1 year had the potential to prevent school dropout [26]. CT programs also have shown potential for CT improving the odds of being enrolled in and attending school, improving household socioeconomic status (SES) and quality of life, and reducing early marriage $[29,30]$. In the trial, we define dropout as not attending school consecutively for at least 1 term or longer. Girls who attended part or all of Form (class) 4, but then do not sit the final national Kenya Secondary Certificate of Education (KSCE) exams will be considered a dropout in that final term. Other secondary school indicators such as grade repetition will also be documented. Girls who return to school after being classified as a dropout will be classified as re-enrolled.

\section{Justification for cumulative risk of incident HIV and HSV-2}

Risky sexual exposure can cause harm to a girl's sexual and reproductive health and negatively affect her lifechances even while remaining in school. The pilot showed high prevalence of laboratory confirmed STIs in this rural area in western Kenya even among primary schoolgirls $(28 \%$ of girls had reproductive tract infections, predominantly bacterial vaginosis) $[26,31]$. Community surveys in the pilot site found an HIV prevalence of $11 \%$ among females under $30 \mathrm{yr}$., rising from $1 \%$ in 15 yr. to $20 \%$ by age 29 [22, 27], and a reported $52 \%$ of girls in this area engaging in transactional sex for money, gifts or services [32]. HSV-2 is the most common cause of genital ulcer disease worldwide, the most prevalent STI in sub-Saharan Africa, and a well-established biomarker for sexual risk behaviour [8, 33, 34]. Evidence suggests HSV-2 prevalence in girls in the study area increases from $10 \%$ in $13-14 \mathrm{yr}$. to $28 \%$ in $15-19 \mathrm{yr}$., and $70 \%$ among the $20-24$ yr. [27, 35].

A trial in Malawi that provided CT to school girls aged 13-22 yr. found that HIV and HSV-2 prevalence were 33 and $70 \%$ lower respectively in CT recipients after $18 \mathrm{~m}$ intervention when compared to controls [8]. Results were supported with reduced frequencies of selfreported sexual activity and less age discordant sex [8]. The impact of menstrual cups on HIV or HSV-2 has not been evaluated, but when assessed during the pilot study, cups were associated with a lower prevalence of STIs and bacterial vaginosis [26], both important risk factors for HIV acquisition and transmission [36-38]. This information corroborates reported narratives that control-arm girls most acutely felt the need to have sex to obtain sanitary pads [24, 25]. Laboratory confirmation of infections is essential, however, as girls and young women's reported symptoms are poorly predictive of infection [31, 39-43].

\section{Study setting}

The study will be conducted in schools in Siaya County in rural western Kenya, extending to contiguous areas that include Kisumu County if needed. The site is in a health and demographic surveillance system (HDSS) positioned $400 \mathrm{~km}$ west of Nairobi, with its southernmost point reaching Lake Victoria [44]. The population are mostly members of the Luo ethnic group, and are mainly subsistence farmers [45]. Siaya is an impoverished area, with previous studies estimating households have a mean annual income approximating $\$ 600$ to $\$ 700$ [46]. An estimated four out of ten child learners miss school daily in Siaya County [47]. Gender equity seen in primary school falls during adolescence, with between 25 and $33 \%$ more boys than girls attending secondary school by age $18[48,49]$. The disease burden typifies rural African communities [44], with mortality in adolescents and young adults attributed to communicable diseases, injuries [50], and maternal causes [51]. Advances in antiretroviral therapy (ART) access have been associated with reducing adolescent and young female mortality by half $[50,52]$. Physical and sexual violence against females is one of the highest in Kenya, with $12 \%$ of women reporting their first sexual intercourse was coerced [53], rising up to $45 \%$ among adolescent girls [54]. The former pilot study evaluating menstrual interventions was conducted in one of the three sub-divisions within the study area, with water, sanitation, and hygiene (WASH) observations illustrating presence of latrines and water, but not soap in schools [23]. The menstrual care among the population was examined and illustrate girls' and young women's preference for commercial pads over traditional items; with $10 \%$ of $15 \mathrm{yr}$. olds reporting they had sex for money to purchase sanitary pads [22]. Schools and health facilities have been geolocated (see Fig. 1, below).

\section{Eligibility criteria: schools Inclusion criteria for schools}

- Secondary school within study area

- Girls or co-educational school

- Day school

- Approval by Head Teacher 


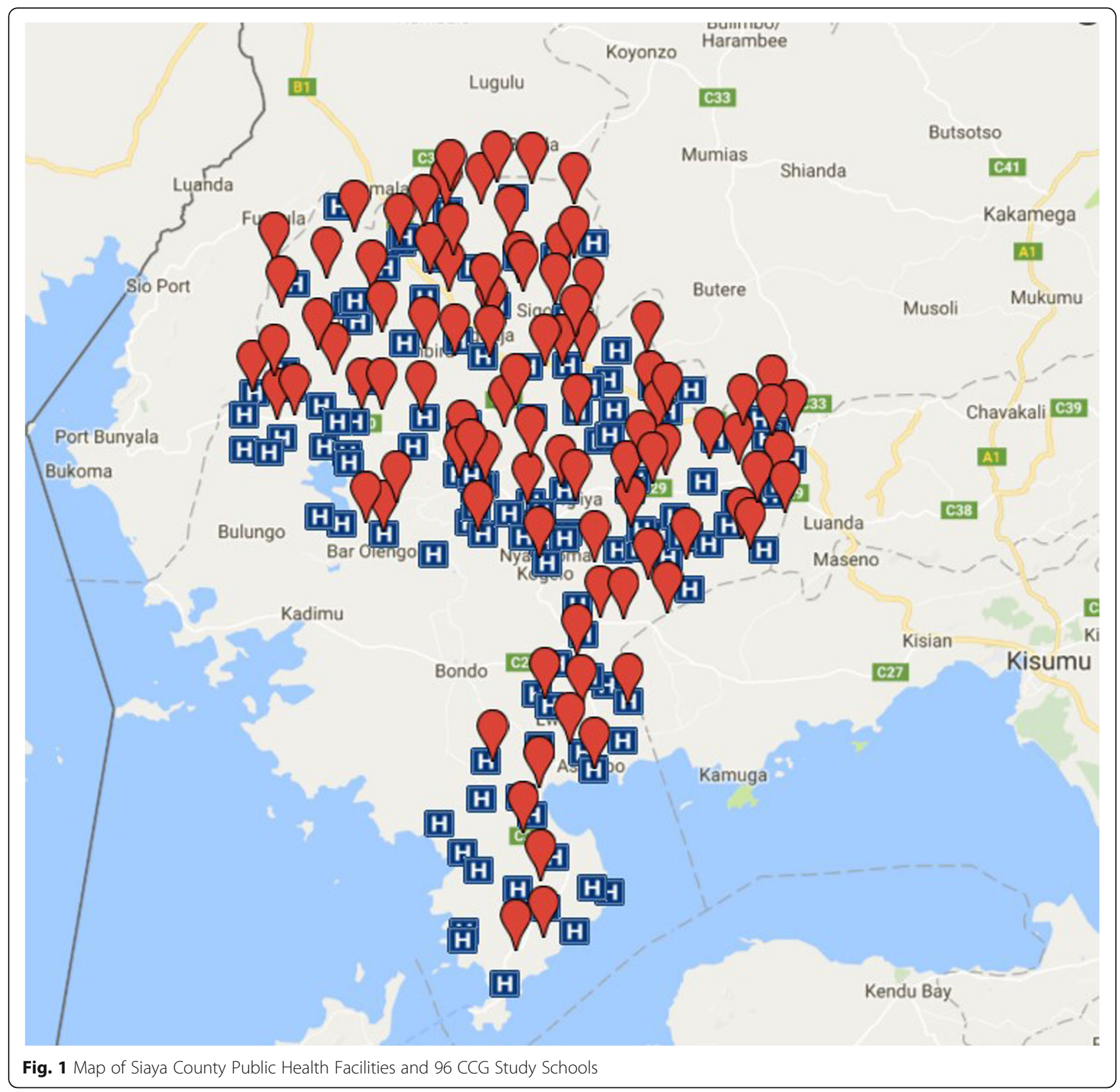

\section{Exclusion criteria for schools}

- Boys only school

- Boarding schools

- Special needs schools (i.e. for the blind)
- Have a history of established menses ( $>=3$ times)

- Have no disability preventing participation

- Assent to participating in the study and have received parent or guardian consent
Eligibility criteria: participants Inclusion criteria for participants

- Attend secondary day schools in the study area

- Resident of the study area

\section{Exclusion criteria for participants}

- Attend boarding schools

- Visibly pregnant or declare pregnancy at baseline (girls who don't declare pregnancy but whose 
delivery dates confirm pregnancy started prior to enrolment will be excluded from the analysis.)

\section{Trial interventions}

Schools will be randomised to one of 4 arms:

1. One menstrual cup with training on safe use and care, with handwash soap termly.

2. Cash transfer (CT) Ksh 1500/term plus financial literacy training.

3. Combined menstrual cup and CT with training on financial literacy and cup safe use and care.

4. 'Usual practice' control (control arm), with handwash soap termly.

All participants regardless of school cluster will receive puberty and hygiene education.

\section{Menstrual cup}

The menstrual cup is a medical grade silicone bell shaped container which is inserted into the vagina to collect menstrual flow, and requires emptying at regular intervals $(4-8 \mathrm{~h})$ [55]. Cleaning by boiling is recommended at the end of each cycle. The Mooncup will be used in the trial [56], selected because it has been tested in the UK $[57,58]$ and internationally $[26,59]$, is produced to ISO 13485:2003 standards, and registered by the U.S. Food and Drug Agency of Medicines (FDA; Registration Number 3009117944); and was successfully used in the pilot study [54]. Further, its' white colour when new, changing to brown after use, allows physical observation of use [26]. Girls will receive school-based training on safe cup use and care (including insertion, emptying, re-insertion, cleansing, and storage). The trial will document girls' use over time.

\section{Cash transfer pocket money}

Cash transfer (CT) programmes are a popular social protection tool in developing countries that aim, among other things, to improve education outcomes and reduce risky sexual behaviour $[8,10,11,60,61]$. A sum of US $\$ 5$ per month ( Ksh500; exchange December 2015) was recommended for future studies. CT programmes which were conditional on attendance have been shown to improve school outcomes more than unconditional or non-monitored [29]. This trial will provide Ksh1500 (US\$15) per term (3 terms per school year) for up to 10 academic terms. Conditionality for CT receipt will be based on $80 \%$ or more school attendance in the previous term, in line with other studies [8,61-64]. After assent, participants in the CT arms will receive school-based financial literacy training and a bank card. For this trial, Equity Bank pre-paid cash cards will be used for minors after obtaining guardian consent. Girls must provide a birth certificate and a guardian ID to receive a bank card. Precautions will be taken to ensure girls have direct access to their accounts but maintain low visibility to minimize the risk of theft, harassment, or violence. School registries will be assessed retrospectively per term to verify school attendance, with spot-checks conducted to minimise risk of falsification of registries. The trial will document girls' use and spending choices over time.

\section{Endpoints / outcome measures}

Primary outcome:

Composite: incident HIV, HSV-2, all-cause school dropout by the end of the study.

Secondary outcomes:

- School dropout

- HSV-2 incidence

- HIV incidence

- Reported sexual behaviour indicators (including age at sexual debut, age-discordance of partners, coercive sex, number of sexual partners, pregnancy, condom use, and use of modern contraceptives)

- School performance indicators (Kenya Certificate of Secondary Education [KCSE] results, grade repetition, prevalence of re-enrolment, and absenteeism)

- Quality of life using EuroQoL and PEDSQL

- Cost-effectiveness of interventions from the societal, including girls', perspective

\section{Safety endpoints}

- Tolerability: any adverse events assessed in a general health questionnaire

- Primary Safety:

- Toxic Shock Syndrome

- Violence associated with interventions provided

- Secondary Safety:

- E. coli growth on sampled cups

- Other emergent harms that may occur with provision of cash pocket money or cups.

\section{Sample size estimates}

Original trial design sample size estimate: Sample size and power calculations were performed for the minimum number of schoolgirls needed in the proposed 4arm trial using sample size calculation software (NCSS/ PASS); calculations were validated using SAS based simulation studies. Five primary comparisons of the primary endpoint were tested: [1] menstrual cup vs usual practice, [2] CT vs usual practice, [3] combined CT and cup vs usual practice, [4] combined CT and cup vs menstrual cup only, and [5] combined CT and cup vs CT only. Calculations were based on a 2-sided alpha of 0.01 
to allow 5 primary comparisons of interest, assuming an ICC value of 0.008 . Taking a target of mid-late Form-1 of schools in the study area gives a sample size average of 46 girls, a 1 yr. enrolment period, a 5\% overall refusal to take part in the study, $20 \%$ refusal at enrolment to consent to HIV testing among participating girls, an average of 10 terms $(\sim 3.3 \mathrm{yr})$ follow-up through the end of Form-4, and $20 \%$ loss to follow-up or refusal to provide biological samples at the end of the study period. Of 46 enrolled girls/school, on average, $35(0.95 * 0.80 \times$ 46) will contribute to the primary analysis; we assume that 6.9 will be HSV-2 or HIV positive on enrolment (24.7\% of 28 girls who agree to testing) and the remaining 28.1 will be HSV-2/HIV negative $(n=21.1)$ or of unknown HSV-2/HIV sero-status $(n=7)$ because no assent/consent was provided for testing at enrolment. With these assumptions, a trial with 4 arms of 21 schools per arm (84 schools total) enrolling 46 girls/ school (i.e. 966/arm; 3864 girls total) with 35 girls/school contributing to analysis, will have $90 \%$ power to detect a $25 \%$ reduction (Relative Risk $[R R]=0.75$ ) in the $3.3 \mathrm{yr}$. incidence risk of the primary endpoint from $44.1 \%$ in the control group to $33.1 \%$ with either intervention, and $80 \%$ power to detect a $22.2 \%$ reduction $(\mathrm{RR}=0.778)$ to $34.3 \%$ (both at alpha $=0.01$ ).

Source data: The ICC value of 0.008 was the observed ICC value for the composite endpoint of school dropout and STIs in our previous pilot study, and 0.0084 for school dropout alone [26]. The anticipated effect sizes of $25 \%(R R=0.75)$ for the primary endpoint is based on a model combining the impact and event frequency of the 3 components of the primary endpoint in the three strata: HSV2/HIV negative girls $(60.2 \%$ of the overall sample), HSV-2 or HIV positive girls (19.8\% of the sample), and girls for whom the sero-status is unknown (20\% of the sample). The model predicts that a $25 \%(R R=0.75)$ overall reduction from 44.1 to $33.1 \%$ with single interventions, or from 33.1 to $24.8 \%$ with the dual intervention can be achieved with the following combination of relative risk reductions for school dropout and HIV and HSV-2 incidence respectively: 30 and $25.7 \%$; 25 and $34.2 \%$; or 20 and $43.0 \%$. The anticipated minimum reduction of $30 \%$ in dropout is based on an average $31 \%$ reduction in a meta-analysis comparing controls against cash transfer [29], and is more conservative than a $58 \%$ reduction observed with menstrual cups in year- 2 of the pilot [26]. The $48.8 \%$ reduction in HIV and HSV-2 incidence is based on a $51.9 \%$ reduction observed in year- 2 of the pilot study, adjusted for the fact that baseline HSV2-HIV status would not be available for 12 of 60 girls/school (20\%) on enrolment, 3 to 4 of whom may have undetected HSV-2 or HIV on enrolment. The observed relative risk reduction in the HIV and HSV-2 incidence was $48.8 \%$ (based on a $43.4 \%$ reduction in STI prevalence by the end of the previous pilot in 2014) [26].

\section{Blinded sample size re-estimation}

A blinded sample size re-estimation was conducted in 2017 using the baseline data from all arms pooled to validate the assumptions made during the original sample size estimations in the trial design phase. The average number of girls per school and the baseline prevalence of HSV-2/HIV (a proxy for the anticipated incidence) were lower than anticipated. A sample size re-estimation with pooled data demonstrated that a total of 96 school clusters (24/arm) are required with an anticipated average of 41.25 girls per cluster to obtain $90 \%$ power to detect a $25 \%(R R=0.75)$ reduction in the primary endpoint from $39.3 \%$ in the control arm to $29.5 \%$ in any of the 3 intervention arms (alpha $=0.0167$ allowing for 3 primary comparisons against the control arm), with an ICC of 0.008 and allowing for $20 \%$ loss to follow-up. This yields a full sample of 3960 overall, 3168 of whom are expected to contribute to the primary endpoint, 33 per cluster. This same sample size provide $80 \%$ power to detect a $25.7 \%(R R=0.743)$ reduction from $29.5 \%$ in any of the single intervention arms to $21.9 \%$ in the combined intervention arm (alpha $=0.025)$. The total sample size may exceed 3960 if the average cluster enrolled has more eligible girls than anticipated as the intention is to give every eligible girl in each secondary school the opportunity to participate.

\section{Assignment of interventions Allocation}

School clusters are the unit of randomisation and girls the unit of measurement. A census of secondary schools in the area will be used to select the eligible schools. The trial statistician will produce block randomized groupings of four schools (blocks) using a 1: 1:1:1 ratio and based on location and size, including larger schools (e.g. with more than 20 target girls) for logistical reasons. Arm allocation of schools to intervention arms will be achieved using community ceremonies. During a public ceremony, head teachers representing their respective school will be called up with the rest of their blocks for balanced randomization. The head teachers will each simultaneously pick 1 of 4 coded items, and once all blocks have completed this process and all schools have been randomly allocated, study arm will be displayed by opening sealed envelopes and breaking the code. This methodology was informed by the pilot study where randomisation ceremonies with head teachers were successful [26]. 


\section{Blinding}

Participants cannot be masked to their treatment arm due to the nature of interventions provided. Laboratory personnel testing for HIV and HSV-2, investigators, and trial statisticians will be blinded to the study arm. Field staff will be masked as much as feasible, including those who conduct home visits to confirm dropout. Bias will also be minimised by use of block randomisation stratified by school size. An independent person will prepare the sealed envelopes with the study arm allocation. Study arm allocation will not be recorded in the central database to ensure the trial statistician and data managers remain blinded throughout the study. This information will be recorded separately and only be merged with the main database following approval of the statistical analysis plan (SAP), closure of the databases and submission of a copy to the independent statistician of the Data Monitoring and Ethics Committee (DMEC).

\section{Participants' timeline Overview}

The participant's timeline will commence after prerecruitment preparations, including ministry, school, and community stakeholder meetings and approvals. Parent consent for their daughters' participation will follow the school cluster randomisation ceremonies. Participants' meetings for assent, pre-screen enrolment and baseline screening, mid-line screening (second study year), and end-line screening (third study year) will be held as 'Health Days' in randomised schools (Fig. 2).

\section{Pre-screen enrolment, assent and baseline screening}

The school enrolment register will be used as the sampling frame to define all target girls in the study schools. Parents of all girls will be approached at the end of the school information meeting to request informed consent for [1] the main study, [2] HIV testing and counselling, and [3] blood storage. Signing will be private and oneto-one with a trained member of the study team. The enrolment list will be updated at the meeting to record girls transferring out or into the school and missed parents will be followed up at home for consent. Reasons for non-consent will be documented.

Girls whose parents have consented to their participation in the study will be informed of the study purpose and procedures. Each girl will individually be asked to give her assent to participate and asked key eligibility criteria questions (see eligibility criteria: participants, above). Girls who meet the eligibility criteria will then be invited to participate in the study.

Participants will privately self-administer a combined demographic, social, behavioural and quality of life/wellbeing questionnaire using tablets during the 'Health Day'; absent girls will be invited to participate at a subsequent 'Health Day' when logistically feasible. All relevant information will be captured in the survey questionnaire. Baseline questions around demographics, use of menstrual items, and access to cash and personal bank account will be asked, as well as other secondary outcomes. Wellbeing will be assessed using the adolescent (12-18 yr) 23-item PedsQL ${ }^{\mathrm{tm}} 4.0$ (Paediatric Quality of Life Inventory; http://www.pedsql.org/), and will measure physical, emotional, social, and school functioning of children, core dimensions as delineated by WHO [65].

A baseline clinical survey will be conducted to define pre-intervention HIV and HSV-2 prevalence, and height, weight, and waist measures of participants. Documentation of population HIV prevalence is important to understand frequency of mother-to-child transmission of HIV, noted in a Zimbabwean schoolgirl CT study which only evaluated HIV and HSV-2 at endline [30]. However, refusal to have an HIV or HSV-2 test at baseline will not preclude participants from joining the study. School 'Health Days' will be operated with a trained mobile team at a location at or close to their school. All sample collection and HIV counselling will be conducted by a team of trained HIV Testing and Counselling (HTC) staff. Results will not be given then, but separately to participants on an individual level at the health clinics with trained counsellors and testing and counselling and care facilities. Participants can visit clinics individually without peer pressure and are encouraged but not obligated to ask their parents to accompany them. If consent/assent has been obtained for blood collection, girls will provide $600 \mathrm{uL}$ of blood for HIV and $1.5 \mathrm{ml}$ for HSV-2 with any blood not used for these two tests stored as dried blood spots for future testing of other STIs or vaccine preventable infections, if funding allows. Blood will be collected through fingerpick and stored and transported in Microtainer EDTA tubes to KEMRI laboratories for analysis. Blood will be stored for a maximum of $5 \mathrm{yr}$, after completion of the trial, after which it will be destroyed.

\section{Midline screening}

All participants will be invited to participate in a midstudy behavioural survey to update socio-behavioural characteristics, including marriage status, sexual exposures, and document patterns of intervention use, problems encountered, and any possible safety issues. Midline HIV/HSV-2 testing will be conducted midstudy. These tests and follow-up counselling and treatment will follow the same methodologies used at baseline. These measurements will allow closer examination of incidence over time and offer the opportunity to test and counsel participants who exit the study before the endline survey. Baseline consents and assents include 


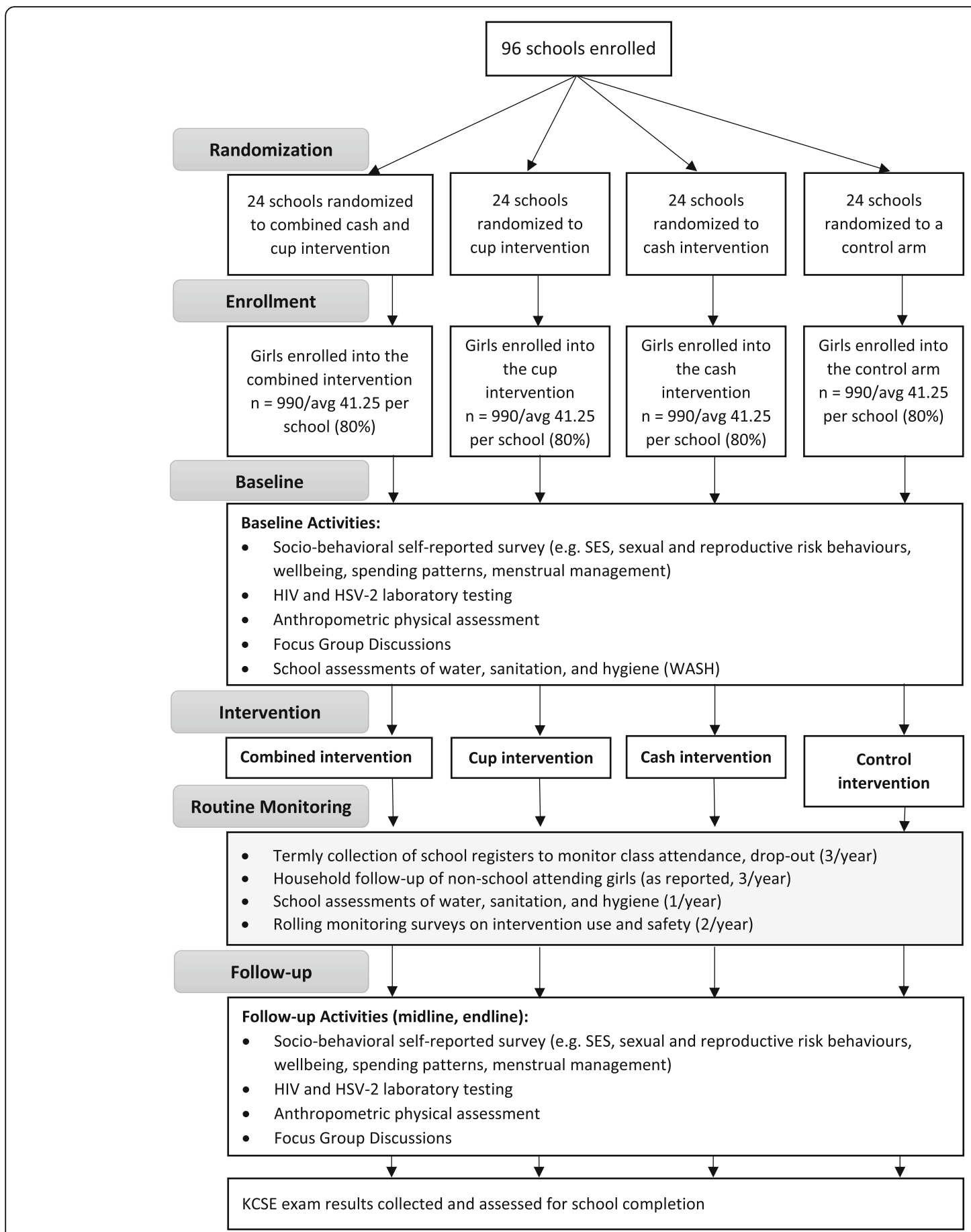

Fig. 2 Flowchart of Randomization and Study Design

this assessment. Participants are reminded they have the freedom to withdraw or refuse testing.

\section{End study screening}

Similar to the baseline Health Day, participants will attend an end of study Health Day to complete an endline behavioural survey to document changes in socio- behavioural characteristics (including risky sexual behaviours, quality of life/wellbeing measures) and intervention use, problems encountered, and any perceived harms. Outreach activities to survey enrolled girls who have left school or dropped out will be conducted if funding is available. HIV and HSV-2 serostatus will be assessed at this same Health Day to determine incidence 
among those testing negative at enrolment and during interim follow-up testing. Careful consideration and coordination with head teachers will be needed to secure the dates for the final survey to ensure no disruption for girls in Form 4 while they take final exams. Endline HIV/HSV-2 testing will be conducted on Health Days in safe spaces among all enrolled girls to protect the confidentiality of baseline HIV positive participants. Participants are reminded they have the freedom to withdraw or refuse testing.

\section{Unscheduled visits}

School dropout will be assessed every term until the study end. Regular monitoring of school registers will be conducted to determine dropout among participating girls. Girls who dropout will be followed-up with an unscheduled visit to the home to understand reasons for dropout and confirmation of the same, and to identify those that have migrated to a different area who may still attend school (e.g. are classified as loss to followup). An unannounced annual WASH survey will be conducted at all participating schools, to observe the presence and state of latrines, water availability, water treatment, handwashing units and soap. At any time, participants displaying adverse events will be assessed by a study nurse, with a triage form evaluating seriousness and potential relationship with the interventions and tailored $\mathrm{AE}$ and $\mathrm{SAE}$ forms to document relevant details (see Additional file 2: SAE Report Form).

\section{Focus group discussions}

FGDs will be held pre-intervention, annually (interim) during the trial, and at the end of the study. Feedback from these will document participant and other beneficiaries understanding of the interventions, use, impact and any problems arising.

\section{Laboratory procedures Clinical testing}

HIV testing will be conducted in accordance to Kenyan national guidelines [66]. HSV-2 will be examined using Kalon gG2 ELISA test kits (Kalon Biologicals Ltd., Guilford, UK), with quality assurance performed. Any additional blood collected at baseline, interim, or end of study will be stored for future testing of other STIs or vaccine preventable infections, if funding allows.

\section{Cup contamination}

A register of all participants receiving cups will be used to randomly select a swatch of used cups by duration of provision. This will exclude girls who received a replacement cup due to loss, theft, or damage. Randomly selected participants will be traced and asked if they are willing to swap their existing cup for a new one, to allow laboratory examination of their cup. Each used cup will be placed in a separate lock- bag labelled with participant ID and transported to the laboratory and tested for $E$ coli growth. Cups will be swabbed using polyester tipped swabs moistened in normal saline and inoculated into both MacConkey (MAC) agar and blood agar (BA) and incubated for $18-24 \mathrm{~h}$ at $37^{\circ} \mathrm{C}$. After incubation, colony types will be visualized for characteristic morphology of E.coli and others from the MAC plates, and subjected first to analytical profile index (API) testing for suspected $E$ coli growth [67], then incubated for 18$24 \mathrm{~h}$ at $37^{\circ} \mathrm{C}$. The results will be interpreted using API software [68].

\section{Statistical methods}

A study statistical analysis plan will be developed during the course of the study for the final analysis. This will be completed prior to the unblinding of data at database lock.

\section{Screening failures}

A participant who gives informed assent (after parental consent) and is provided with a study ID, but then is found not to fulfil the eligibility criteria, will be classified as a screening failure and excluded from the intentionto-treat (ITT) and the per protocol (PP) analysis. Pregnant girls who do not declare pregnancy at enrolment will be excluded from analysis after the dates of normal (or otherwise) deliveries confirm that the current pregnancy was ongoing at enrolment.

Intention-to-treat (ITT) population.

The intention-to-treat population (the full analysis population) is defined as all participants who provided parental consent, themselves assented, and were enrolled into the study. These girls will be included in the intention-to-treat analysis regardless of whether they have completed all endline evaluations.

Per protocol (PP) population.

The per-protocol population within the menstrual cup groups is defined as all participants receiving the cup with evidence showing actual use. For cash transfer, 'per protocol' constitutes all girls receiving the cash intervention until dropout or reaching the endpoint. Participants documented to have crossed over between school clusters will be excluded.

\section{Cost-effectiveness analyses}

An economic evaluation will be conducted to provide evidence for the cost-effectiveness of the three interventions. This will be used to estimate the societal cost consequences and efficiencies of the intervention packages to inform health service delivery and future policy decisions. 


\section{Safety outcomes}

Adverse events (AEs) and serious adverse events (SAEs) will be monitored, managed and recorded during the study (see Additional file 2: SAE Report Form). AEs will be reported and tabulated for each treatment arm, overall, and according to body system on a per protocol basis. Intervention emergent AEs are defined as adverse events that had an onset on the day of the intervention, or thereafter. AEs that have missing onset dates will be considered to be treatment emergent. No formal statistical testing will be undertaken. All laboratory data will be listed and summarised.

\section{Ethics approval and consent to participate}

This protocol, the informed parent consent and participant assent documents, and participant information sheets have been reviewed and approved by the Research Ethics Committees at the Kenya Medical Research Institute, Nairobi, Kenya (KEMRI protocol \#3215) and the Liverpool School of Tropical Medicine, Liverpool (LSTM protocol \#15-005). The Centers for Disease Control and Prevention gave approval for reliance on the KEMRI IRB (2016-136). Registry approval for trailing menstrual cups was given by the Kenyan Poisons and Pharmacy Board (ECT_16_07_06). Annual renewal of approvals by KEMRI, LSTM, and KPPB are required based on reporting of trial activities in the prior year.

\section{Discussion}

In this study we are hypothesizing that, as a result of receiving the trial interventions, participating adolescent girls' health and schooling will improve. Prior studies have illustrated that the provision of a menstrual cup can lower rates of reproductive tract and sexually transmitted infections [26]; and that the provision of cash transfer impacts positively on girls' schooling outcomes $[8,13]$. Moreover, evidence is building that enrolment and consistent attendance in school acts as a social vaccine with multiple benefits for girls $[6,15]$. This trial will determine if provision of a menstrual solution alone, or in combination with cash transfer directly to schoolgirls can improve their life chances, in terms of reducing their risk of HIV, STI (HSV-2), and school dropout. In our trial, we postulate the interventions tested (cups alone, $\mathrm{CT}$ alone, or cups and $\mathrm{CT}$ ) will lead to a reduction in schoolgirls' exposure to sexual and reproductive harms, while increasing their opportunity to complete their schooling, compared with controls. Enrolment, intervention and follow-up of participants across a wide geographical area in rural Africa requires a strong collaboration with schools, communities and organisations. The collaboration in western Kenya between KEMRI, LSTM, SWAP, CDC and government of Kenya (GoK) provides this. Parallel small group sessions evaluating programme fidelity and uptake will inform and strengthen the development of programmatic materials for implementation, should the trial show positive outcomes.

Our research will be communicated to the UK and Kenyan public, Kenyan local, county and national ministries, NGO and aid agencies, national and international universities, research groups, international development and aid agencies, donor organizations, and international agencies setting global policy. We will use multiple communication strategies to target information to the correct audience, as appropriate. Much will be through face-to-face interactions at workshops, meetings, local forum presentations, and international conferences. Communication through technology transfer will be used to disseminate more widely to a broader audience, through online networks, webinars, online news, blogs, and publication portals.

We hope that if the interventions prove to be successful and our communication strategy sound, this trial could contribute to improved retention of adolescent girls in school, and could have multiple benefits for health and education services, and national and global level development. This growing evidence base must be used to help girls complete their educations and become financially independent adults, better manage their own menstrual hygiene, and reduce the negative psychosocial pressures and stigma leading to sexual exploitation, violence, illness, premature marriage, and death during childbirth. Cascading benefits may include that communities will benefit from an increase in social capital, and a reduction in resources required to support unemployed, sick, and pregnant girls. Evidence-basedpolicy will lead to schools being beneficiaries, by improving girls' experience of menstrual care in school; and teachers will benefit from girls' improved attention in class and equitable teaching. As more girls complete education, there will be greater opportunity for training female teachers, redressing the gender imbalance. More engaged pupils will increase teachers' job satisfaction and better grades will raise school profiles. Partnerships between education and the health sector will be strengthened. Economic benefits would translate nationally; for example, researchers estimate that in Kenya, if all $1.6 \mathrm{~m}$ adolescent girls were able to complete secondary school, and the $\sim 220,000$ girls who were pregnant and delivered could be educated, there would be a cumulative effect adding up to $£ 2.1$ billion towards Kenya's gross income per year [4]. Implementation of successful interventions globally will increase the number of girls completing school, reducing the current global estimate of $44 \mathrm{~m}$ adolescent girls out of school. Implementing interventions that retain girls through secondary school will have global economic benefits, 
as it is estimated that countries growth rates would increase on average by $\sim 1 \%$ annually if girls' education was raised one level higher (i.e. secondary status). Interventions will reduce the prevalence of teen births and poor maternal outcomes, and the rate of new HIV infections in adolescence which currently account for $\sim 40 \%$ of new infections. This will decrease the burden of HIV programme costs for antiretroviral drugs and antenatal care to prevent mother to child transmission.

\section{Supplementary information}

Supplementary information accompanies this paper at https://doi.org/10. 1186/s12889-019-7594-3.

Additional file 1. SPIRIT Checklist

Additional file 2.SAE Report Form

\section{Abbreviations}

95\% Cl: 95\% Confidence Interval; AE: Adverse event; AIDS : Acquired Immunodeficiency Syndrome; ART: Antiretroviral therapy; CDC: Centers for Disease Control and Prevention; CHW: Community Health Worker; CRF: Case Record Form; CRO: Contract Research Organization; CT: Cash transfer; DfID: Department for International Development, UK; DHSC: UK Department of Health and Social Care; DMEC: Data Monitoring and Ethics Committee; DSMB: Data Safety Monitoring Board; ELISA: Enzyme linked immunosorbent assay; ERC: Ethics Research Committee; FDA: Food and Drug Administration; FGD: Focus group discussions; GCP: Good Clinical Practice; GEE: Generalised Estimating Equation; GMP: Good Manufacturer Practice; HDSS: Health and Demographic Surveillance System; HIV: Human immunodeficiency virus; HSV2: Human simplex virus type 2; HTC: HIV testing and counselling; IDI: Indepth interviews; IRB: Institutional Review Board; ITT: Intention to Treat; JGHT: Joint Global Health Trials; KEMRI: Kenya Medical Research Institute; LSTM: Liverpool School of Tropical Medicine; MHM: Menstrual hygiene management; MoEST: Ministry of Education, Science and Technology; MoH: Ministry of Health; MRC: Medical Research Council, UK; PCR: Polymerase Chain Reaction; PE: Protective efficacy; PP: Per protocol; QoL: Quality of life; RCT: Randomised Controlled Trial; REC: Research Ethics Committee; RR: Relative risk; RTI: Reproductive tract infections; SAE: Serious adverse event; SAP: Statistical Analysis Plan; SOP: Standard Operating Procedure; SRH: Sexual and reproductive health; STI: Sexually transmitted infections; SWAP: Safe Water and AIDS Project; tCTU: Tropical Clinical Trials Unit; TSC: Trial Steering Committee; WASH: Water, sanitation and hygiene; WHO: World Health Organization

\section{Acknowledgements}

We are most grateful for the valuable advice and comments of the independent Trial Steering Committee members (Robert Bailey, Sarah Baird, Marni Sommer, Sassy Molyneux, Caroline Kabiru, Christian Borja-Vega, Jo Mulligan), and of the Data Monitoring and Ethics Committee members (Michelle Hindin, Helen Weiss, and Jackton Omoto). We would also like to thank the LSTM programme manager (Cheryl Giddings), research management services, and research governance teams. Further thanks to Mooncups ${ }^{\oplus}$ Ltd., UK, for supplying the menstrual cups at a discounted rate; and Equity Bank, Kenya for advice and support of the cash dispersal system. Additional thanks to the dedicated field, lab, admin, and office staff; to the Ministry of Health and Education partners, administrative leaders, schools, and communities, and importantly to the girls and their families in Siaya County. This paper is published with the permission of KEMRI Director. The findings and conclusions in this paper are those of the authors and do not necessarily represent the official position of the Centers for Disease Control and Prevention.

\section{Authors' contributions}

PPH and FtK conceived the study. PPH, FtK, DK, DW, EZG, LM, AE, LN, AvE, and $\mathrm{CO}$ wrote the grant. PPH, GZ, FtK, DK, EN, EZG, LM, AvE, CO, JJ, EK, MM $\mathrm{DO}, \mathrm{BO}$, and $\mathrm{GB}$ drafted the protocol. DW and TC provided statistical guidance in the protocol, IN provided ministry and policy expertise, $\mathrm{CH}$ guided drafting of trial governance, and CP drafted the safety monitoring procedures. All investigators contributed to the refinement of the study protocol and approved the final version. GZ, PPH, AvE, FtK, LM, DK, TC, EZG, and DW drafted the manuscript. All authors read and approved the final manuscript prior to submission.

\section{Funding}

This study is funded by the Joint Global Health Trials Initiative (UK-Medical Research Council/Department for International Development/Wellcome Trust /Department of Health and Social Care, grant MR/N006046/1). The funders have or will have no role in the design of the study, the collection, analysis, and interpretation of data, or in writing the manuscript.

\section{Availability of data and materials}

Not applicable: Out manuscript does not contain any data or related findings.

\section{Ethics approval and consent to participate}

This protocol, the informed parent consent and participant assent documents, and participant information sheets have been reviewed and approved by the Research Ethics Committees at the Kenya Medical Research Institute, Nairobi, Kenya (KEMRI protocol \#3215) and the Liverpool School of Tropical Medicine, Liverpool (LSTM protocol \#15-005). These ethics approvals cover all 96 participating Siaya schools. The Centers for Disease Control and Prevention gave approval for reliance on the KEMRI IRB (2016-136). Registry approval for trailing menstrual cups was given by the Kenyan Poisons and Pharmacy Board (ECT_16_07_06). Annual renewal of approvals by KEMRI, LSTM, and KPPB are required based on reporting of trial activities in the prior year. Written parent consents and written participant assents were collected. In the case that a parent was illiterate and could not read, verbal consent with a witnessing literate adult of the parents choosing was collected.

\section{Consent for publication}

Not applicable.

\section{Competing interests}

The authors declare no conflict of interests.

\section{Author details}

'Department of Clinical Sciences, Liverpool School of Tropical Medicine, Pembroke Place, Liverpool L3 5QA, UK. ${ }^{2}$ Centre for Global Health Research, Kenya Medical Research Institute (KEMRI), Kisumu, Kenya. ${ }^{3}$ Center for Global Health, Division of Global Health HIV and TB, U.S. Centers for Disease Control and Prevention (CDC), Nairobi, Kenya. ${ }^{4}$ Safe Water and AIDS Project (SWAP), Kisumu, Kenya. ${ }^{5}$ Ministry of Health, Siaya County, Kenya.

\section{Received: 19 February 2019 Accepted: 4 September 2019}

Published online: 21 October 2019

\section{References}

1. Viner RM, Ozer EM, Denny S, Marmot M, Resnick M, Fatusi A, et al. Adolescence and the social determinants of health. Lancet. 2012;379(9826):1641-52.

2. Patton GC, Coffey C, Sawyer SM, Viner RM, Haller DM, Bose K, et al. Global patterns of mortality in young people: a systematic analysis of population health data. Lancet. 2009;374(9693):881-92.

3. Bearinger $\mathrm{LH}$, Sieving RE, Ferguson J, Sharma V. Global perspectives on the sexual and reproductive health of adolescents: patterns, prevention, and potential. Lancet. 2007;369(9568):1220-31.

4. Chaaban J, Cunningham W. Measuring the Economic Gain of Investing in Girls - The Girl Effect Dividend. Washington: World Bank; 2011. Report No.: 5753

5. Doyle AM, Weiss HA, Maganja K, Kapiga S, McCormack S, Watson-Jones D, et al. The long-term impact of the MEMA kwa Vijana adolescent sexual and reproductive health intervention: effect of dose and time since intervention exposure. PLoS One. 2011;6(9):e24866

6. Jukes $\mathrm{M}$, Simmons $\mathrm{S}$, Bundy D. Education and vulnerability: the role of schools in protecting young women and girls from HIV in southern Africa. Aids. 2008;22(Suppl 4):S41-56.

7. Biddlecom A, Gregory R, Lloyd CB, Mensch BS. Associations between premarital sex and leaving school in four sub-Saharan African countries. Stud Fam Plan. 2008;39(4):337-50. 
8. Baird SJ, Garfein RS, Mclntosh CT, Ozler B. Effect of a cash transfer programme for schooling on prevalence of HIV and herpes simplex type 2 in Malawi: a cluster randomised trial. Lancet. 2012;379(9823):1320-9.

9. UN. The Sustainable Development Goals Report 2016. New York: United Nations; 2016

10. Cluver L, Boyes M, Orkin M, Pantelic M, Molwena T, Sherr L. Child-focused state cash transfers and adolescent risk of HIV infection in South Africa: a propensityscore-matched case-control study. Lancet Glob Health. 2013;1(6):e362-70.

11. Handa S, Halpern CT, Pettifor A, Thirumurthy H. The government of Kenya's cash transfer program reduces the risk of sexual debut among young people age 15-25. PLoS One. 2014;9(1):e85473.

12. Cho H, Mbai I, Luseno WK, Hobbs M, Halpern C, Hallfors DD. School support as structural HIV prevention for adolescent orphans in western Kenya. J Adolesc Health. 2018;62(1):44-51.

13. Cho H, Ryberg RC, Hwang K, Pearce LD, Iritani BJ. A school support intervention and educational outcomes among orphaned adolescents: results of a cluster randomized controlled trial in Kenya. Prev Sci. 2017;18(8): 943-54.

14. Grant M, Hallman K. Pregnancy-related school drop-out and prior school performance in south Africa. New York: Population Council; 2006.

15. Hargreaves J, Morison L, Kim J, Bonell C, Porter J. al. e. the association between school attendance, HIV infection and sexual behaviour among young people in rural South Africa. J Epidemiol Community Health. 2008:62: 113-9.

16. Juma M, Askew I, Alaii J, Bartholomew LK, van den Borne B. Cultural practices and sexual risk behaviour among adolescent orphans and nonorphans: a qualitative study on perceptions from a community in Western Kenya. BMC Public Health. 2014;14:84.

17. Oruko K, Nyothach E, Zielinski-Gutierrez E, Mason L, Alexander K, Vulule J, et al. 'He is the one who is providing you with everything so whatever he says is what you do': A Qualitative Study on Factors Affecting Secondary Schoolgirls' Dropout in Rural Western Kenya. PloS one. 2015;10(12): e0144321.

18. Nobelius A-M, Kalina B, Pool R, Whitworth J, Chesters J, Power R. "You still need to give her a token of appreciation": the meaning of the exchange of money in the sexual relationships of out-of-school adolescents in rural Southwest Uganda. J Sex Res. 2010;47(5):490-503.

19. Wamoyi J, Fenwick A, Urassa M, Zaba B, Stones W. "Women's bodies are shops": beliefs about transactional sex and implications for understanding gender power and HIV prevention in Tanzania. Arch Sex Behav. 2011;40(1):5-15.

20. Sommer M, Caruso BA, Sahin M, Calderon T, Cavill S, Mahon T, et al. A time for global action: addressing Girls' menstrual hygiene management needs in schools. PLoS Med. 2016;13(2):e1001962.

21. Sommer M, Sahin M. Overcoming the taboo: advancing the global agenda for menstrual hygiene management for schoolgirls. Am J Public Health. 2013;103(9):1556-9.

22. Phillips-Howard PA, Otieno G, Burmen B, Otieno F, Odongo F, Odour C, et al. Menstrual needs and associations with sexual and reproductive risks in rural Kenyan females: a cross-sectional behavioral survey linked with HIV prevalence. J Women's Health (Larchmt). 2015;24(10):801-11.

23. Alexander K, Oduor C, Nyothach E, Laserson K, Amek N, Eleveld A, et al. Water, sanitation and hygiene conditions in Kenyan rural schools: are schools meeting the needs of menstruating girls? Water. 2014;6:1453-66

24. Mason L, Nyothach E, Alexander K, Odhiambo FO, Eleveld A, Vulule J, et al. 'We keep it secret so no one should know' - a qualitative study to explore young schoolgirls attitudes and experiences with menstruation in rural Western Kenya. PloS one. 2013;8(11):e79132.

25. Mason L, Laserson K, Oruko K, Nyothach E, Alexander K, Odhiambo F, et al. Adolescent schoolgirls' experiences of menstrual cups and pads in rural western Kenya: a qualitative study. Waterlines. 2015;34(1):15-30.

26. Phillips-Howard P, Nyothach E, ter Kuile F, Omoto J, Wang D, Zeh C, et al, Menstrual cups and sanitary pads to reduce school attrition, and sexually transmitted and reproductive tract infections: a cluster randomised controlled feasibility study in rural western Kenya. BMJ Open. 2016;6: e013229.http://dx.doi.org/https://doi.org/10.1136/bmjopen-2016-013229.

27. Amornkul PN, Vandenhoudt H, Nasokho P, Odhiambo F, Mwaengo D, Hightower A, et al. HIV prevalence and associated risk factors among individuals aged 13-34 years in rural Western Kenya. PLoS One. 2009:4(7):e6470.

28. Buve A, Weiss HA, Laga M, Van Dyck E, Musonda R, Zekeng L, et al. The epidemiology of gonorrhoea, chlamydial infection and syphilis in four African cities. Aids. 2001;15(Suppl 4):S79-88.
29. Baird S, Ferreira FHG, Özler B, Woolcock M. Conditional, unconditional and everything in between: a systematic review of the effects of cash transfer programmes on schooling outcomes. J Dev Effect. 2015;6(1):1-43.

30. Hallfors DD, Cho H, Rusakaniko S, Mapfumo J, Iritani B, Zhang L, et al. The impact of school subsidies on HIV-related outcomes among adolescent female orphans. J Adolesc Health. 2015;56(1):79-84.

31. Kerubo E, Laserson KF, Otecko N, Odhiambo C, Mason L, Nyothach E, Oruko KO, Bauman A, Vulule J, Zeh C, Phillips-Howard PA. Prevalence of reproductive tract infections and the predictive value of girls' symptombased reporting: findings from a cross-sectional survey in rural western Kenya. Sex Transm Infect. 2016;92(4):251-6.

32. Juma M, Alaii J, Bartholomew LK, Askew I, Van den Borne B. Risky sexual behavior among orphan and non-orphan adolescents in Nyanza Province, Western Kenya. AIDS Behav. 2013;17(3):951-60.

33. Obasi A, Mosha F, Quigley M, Sekirassa Z, Gibbs T, Munguti K, et al. Antibody to herpes simplex virus type 2 as a marker of sexual risk behavior in rural Tanzania. J Infect Dis. 1999;179(1):16-24.

34. Luseno WK, Hallfors DD, Cho H, Iritani BJ, Adze J, Rusakaniko S, et al. Use of HIV and HSV-2 biomarkers in sub-saharan adolescent prevention research: a comparison of two approaches. J Prim Prev. 2014;35(3):181-91.

35. Otieno FO, Ndivo R, Oswago S, Pals S, Chen R, Thomas T, Kunneke E, Mills LA, McLellan-Lemal E. Correlates of prevalent sexually transmitted infections among participants screened for an HIV incidence cohort study in Kisumu, Kenya. Int J STD AIDS. 2015;26(4):225-37.

36. Atashili J, Poole C, Ndumbe PM, Adimora AA, Smith JS. Bacterial vaginosis and HIV acquisition: a meta-analysis of published studies. Aids. 2008;22(12): 1493-501.

37. Cohen CR, Lingappa JR, Baeten JM, Ngayo MO, Spiegel CA, Hong T, et al. Bacterial vaginosis associated with increased risk of female-to-male HIV-1 transmission: a prospective cohort analysis among African couples. PLoS Med. 2012;9(6):e1001251

38. Mitchell C, Balkus JE, Fredricks D, Liu C, McKernan-Mullin J, Frenkel LM, et al. Interaction between lactobacilli, bacterial vaginosis-associated bacteria, and HIV type 1 RNA and DNA genital shedding in U.S. and Kenyan women. AIDS Res Hum Retrovir. 2013;29(1):13-9.

39. Jespers V, Crucitti T, Menten J, Verhelst R, Mwaura M, Mandaliya K, et al. Prevalence and correlates of bacterial vaginosis in different sub-populations of women in sub-Saharan Africa: a cross-sectional study. PLoS One. 2014; 9(10):e109670

40. Jespers V, van de Wijgert J, Cools P, Verhelst R, Verstraelen H, Delany-Moretlwe $S$, et al. The significance of Lactobacillus crispatus and $L$ vaginalis for vaginal health and the negative effect of recent sex: a cross-sectional descriptive study across groups of African women. BMC infectious diseases. 2015;15:115.

41. Mlisana K, Naicker N, Werner L, Roberts L, van Loggerenberg F, Baxter C, et al. Symptomatic vaginal discharge is a poor predictor of sexually transmitted infections and genital tract inflammation in high-risk women in South Africa. J Infect Dis. 2012;206(1):6-14.

42. Romoren M, Sundby J, Velauthapillai M, Rahman M, Klouman E, Hjortdahl P. Chlamydia and gonorrhoea in pregnant Batswana women: time to discard the syndromic approach? BMC Infect Dis. 2007;7:27.

43. Romoren M, Velauthapillai M, Rahman M, Sundby J, Klouman E, Hjortdahl P. Trichomoniasis and bacterial vaginosis in pregnancy: inadequately managed with the syndromic approach. Bull World Health Organ. 2007;85(4):297-304.

44. Odhiambo FO, Laserson KF, Sewe M, Hamel MJ, Feikin DR, Adazu K, et al. Profile: the KEMRI/CDC health and demographic surveillance system-Western Kenya. Int J Epidemiol. 2012;41(4):977-87.

45. Cohen D, Atieno-Odhiambo E. Siaya: the historical anthropology of an African landscape. London: James Currey, Ltd; 1989.

46. Meltzer MI, Terlouw DJ, Kolczak MS, Odhacha A, ter Kuile FO, Vulule JM, et al. The household-level economics of using permethrin-treated bed nets to prevent malaria in children less than five years of age. Am J Trop Med Hyg. 2003;68(4):149-60.

47. UWESO. Are Our Children Learning? Nairobi: Annual Learning Assessment Report; 2011. http://www.uwezo.net/publications/reports/ (accessed 1st June 2013); 2012

48. Mensch BS, Clark WH, Lloyd CB, Erulkar AS. Premarital sex, schoolgirl pregnancy, and school quality in rural Kenya. Stud Fam Plan. 2001;32(4): 285-301.

49. Mensch BS, Lloyd CB. Gender differences in the schooling experiences of adolescents in low-income countries: the case of Kenya. Stud Fam Plan. 1998;29(2):167-84 
50. Phillips-Howard PA, Odhiambo FO, Hamel M, Adazu K, Ackers M, van Eijk AM, et al. Mortality trends from 2003 to 2009 among adolescents and young adults in rural Western Kenya using a health and demographic surveillance system. PLoS One. 2012;7(11):e47017.

51. Desai M, Phillips-Howard PA, Odhiambo FO, Katana A, Ouma P, Hamel MJ, et al. An analysis of pregnancy-related mortality in the KEMRI/CDC health and demographic surveillance system in Western Kenya. PLoS One. 2013; 8(7):e68733.

52. Gargano JW, Laserson K, Muttai H, Odhiambo F, Orimba V, Adamu-Zeh M, et al. The adult population impact of HIV care and antiretroviral therapy in a resource poor setting, 2003-2008. Aids. 2012;26(12):1545-54.

53. KNBS. Kenya Demographic and Health Survey 2008-09. Nairobi: National Bureau of Statistics (KNBS) and ICF Macro; 2010.

54. Hewett PC, Mensch BS, Erulkar AS. Consistency in the reporting of sexual behaviour by adolescent girls in Kenya: a comparison of interviewing methods. Sex Transm Infect. 2004;80(Suppl 2):43-8.

55. Obsidian. Menstrual Cups. https://menstrualcups.wordpress.com/ (Accessed 4 March 2017).

56. Mooncups. Advice and Facts : <http://www.mooncup.co.uk/advice-centre/ faqs.html $>$ (last accessed 4 March 2017). October 25th 2011.

57. Stewart K, Powell M, Greer R. An alternative to conventional sanitary protection: would women use a menstrual cup? J Obstet Gynaecol, 2009;29(1):49-52.

58. Stewart K, Greer R, Powell M. Women's experience of using the Mooncup. J Obstet Gynaecol. 2010;30(3):285-7.

59. Oster $E$, Thornton R. Determinants of technology adoption: peer effects in menstrual cup up-take. J Eur Econ Assoc. 2012;10(6):1263-93.

60. Miller T, Hallfors D, Cho H, Luseno W, Waehrer G. Cost-effectiveness of school support for orphan girls to prevent HIV infection in Zimbabwe. Prev Sci. 2013;14(5):503-12.

61. Alam A, Biez J, Del Carpio X. Does Cash for School Influence Young Women's Behavior in the Longer Term? New York: The World Bank; 2011. Contract No.: 5669

62. Galárraga O, Gertler PJ. Conditional cash \& adolescent risk behaviors: Evidence from urban Mexico. Policy Research Working Paper; 2009.

63. Attanasio $\mathrm{O}$, Battistin $\mathrm{E}$, Fitzsimons $\mathrm{E}$, Vera-Hernandez M. How effective are conditional cash transfers? Evidence from Colombia; 2005.

64. Pettifor A. Effects of cash transfer and community mobilization in young South African women; 2012.

65. Varni JW, Burwinkle TM, Seid M. The PedsQL 4.0 as a school population health measure: feasibility, reliability, and validity. Qual Life Res. 2006;15(2):203-15.

66. NASCOP. The Kenya HIV Testing Services Guidelines. Nairobi: National AIDS and STI Control Programme (NASCOP) Ministry of Health; 2015. Report No: ISBN - 139789966038074

67. Blazevic D, Ederer G. Principals of biochemical tests in diagnostic microbiology. New York: Wiley; 1975.

68. Bernasconi C, Volponi G, Bonadonna L. Comparison of three different media for the detection of E. coli and coliforms in water. Water Sci Technol. 2006; 54(3):141-5.

\section{Publisher's Note}

Springer Nature remains neutral with regard to jurisdictional claims in published maps and institutional affiliations.

Ready to submit your research? Choose BMC and benefit from:
- fast, convenient online submission
- thorough peer review by experienced researchers in your field
- rapid publication on acceptance
- support for research data, including large and complex data types
- gold Open Access which fosters wider collaboration and increased citations
- maximum visibility for your research: over 100M website views per year
At BMC, research is always in progress.
Learn more biomedcentral.com/submissions

